\title{
Germination Induces Accumulation of Specific Proteins and Antifungal Activities in Corn Kernels
}

\author{
B. Z. Guo, Z.-Y. Chen, R. L. Brown, A. R. Lax, T. E. Cleveland, J. S. Russin, A. D. Mehta, \\ C. P. Selitrennikoff, and N. W. Widstrom
}

First and ninth authors: Plant Resistance/Germplasm Enhancement Research Unit, Agricultural Research Service, U.S. Department of Agriculture, Tifton, GA 31793; second and sixth authors: Department of Plant Pathology and Crop Physiology, Louisiana State University Agricultural Center, Baton Rouge 70803; third, fourth, and fifth authors: Southern Regional Research Center, Agricultural Research Service, U.S. Department of Agriculture, New Orleans, LA 70179; seventh author: Department of Botany, North Carolina State University, Raleigh 27695; eighth author: Department of Cellular and Structural Biology, University of Colorado Health Sciences Center, Denver 80262.

Accepted for publication 25 July 1997.

\begin{abstract}
Guo, B. Z., Chen, Z.-Y., Brown, R. L., Lax, A. R., Cleveland, T. E., Russin, J. S., Mehta, A. D., Selitrennikoff, C. P., and Widstrom, N. W. 1997. Germination induces accumulation of specific proteins and antifungal activities in corn kernels. Phytopathology 87:1174-1178.

This study examined protein induction and accumulation during imbibition and germination of corn kernels, as well as antifungal activities of extracts from germinating kernels against Aspergillus flavus and $\mathrm{Fu}$ sarium moniliforme. Genotypes studied included GT-MAS:gk and Mp420, which are resistant to A. flavus infection and aflatoxin accumulation, and Pioneer 3154 and Deltapine G-4666, which are susceptible to A. flavus infection and aflatoxin accumulation. Sodium dodecyl sulfate-polyacrylamide gel electrophoresis resolved five protein bands that were present at higher concentrations in germinated kernels than in nongerminated ker-

mulated to a higher concentration in germinated kernels. Two protein bands from dry kernels that reacted with ribosome-inactivating protein (RIP) antiserum were identified as the 32-kDa proRIP-like form and an 18 -kDa peptide of the two peptides that form active RIP. However, in germinated kernels, two protein bands that reacted with RIP antiserum were identified as two RIP-like peptides with a molecular mass of $\approx 18$ and $9 \mathrm{kDa}$. Purified RIP and zeamatin from corn inhibited growth of $A$. flavus. Bioassays of germinated kernel extracts from all four genotypes exhibited antifungal activity against $A$. flavus and $F$. moniliforme, with extracts from the susceptible genotypes showing greater inhibition zones. This study provides evidence of protein induction in corn kernels during imbibition or the early stages of germination, and the induced proteins may be related to our previous findings of germination-associated resistance in the corn kernel, especially in the susceptible kernels.
\end{abstract} nels. Western blot analyses revealed that one of these proteins reacted with the $22-\mathrm{kDa}$ zeamatin antiserum, and a zeamatin-like protein accu-
Additional keywords: biochemical mechanism, maize, mycotoxin, Zea mays.
Pre- and postharvest infection of corn (Zea mays L.) kernels by Aspergillus flavus Link:Fr. is a serious problem, because the fungus produces aflatoxins that are toxic and carcinogenic in animals and a particular human health concern (3). Efforts have been made during the past two decades to reduce grain contamination by aflatoxin. Host-plant resistance is considered the most effective method for reducing aflatoxin accumulation in grain (3), but resistant germ plasm is limited. Plants defend themselves successfully against microbial attack by mechanisms that are constitutive or induced in response to infection by microorganisms and environmental changes $(6,19)$. In the corn- $A$. flavus pathosystem, factors that contribute to resistance in corn kernels to A. flavus and aflatoxin accumulation may include pericarp structure, such as thickness and surface wax $(12,13,25)$, and subpericarp components, such as preformed or induced proteins that inhibit fungal growth or aflatoxin production $(8,11)$. Determining the biochemical and molecular basis of hostplant resistance to plant pathogens has drawn much attention in the pursuit of solutions to plant disease problems, using new biotechnology to improve host resistance $(3,7,28)$.

In many plant-pathogen interactions, inducible pathogenesis-related (PR) proteins, have been well documented (21). In corn, PR

Corresponding author: B. Z. Guo; E-mail address: bguo@tifton.cpes.peachnet.edu

Publication no. P-1997-0908-01R

This article is in the public domain and not copyrightable. It may be freely reprinted with customary crediting of the source. The American Phytopathological Society, 1997 proteins include hydrolases (chitinases and $\beta$-1,3-glucanases), which degrade structural polysaccharides of the fungal cell wall (14); ribosome-inactivating proteins (RIP), which modify and inactivate foreign ribosomes $(1,30)$; and zeamatin, which increases permeability of fungal cell membranes (24).

In a previous study (11), we found that the susceptibility of susceptible corn genotypes was reduced when kernels were incubated at $100 \%$ relative humidity $(\mathrm{RH})$ for 3 days prior to infection with A. flavus, which resulted in a higher rate of germination and lower aflatoxin accumulation than kernels not subjected to preincubation. This germination-associated resistance phenomenon was found elsewhere (16) and may be related to the living embryo of kernels (2). Preincubation under high RH may activate the embryo and induce defense mechanisms. Killing the embryo resulted in high aflatoxin accumulation in susceptible as well as in resistant genotypes (2). Results from these studies may indicate that the viable embryo exerts a profound influence over kernel resistance and that metabolic processes, perhaps PR protein synthesis (4), induced during an early stage of germination may be an important defense mechanism against pathogens.

The objective of this study was to examine whether germination-associated resistance in corn kernels was related to the induction of proteins through (i) investigation of the influence of corn kernel germination on protein induction, (ii) determination of the expression of known antifungal proteins with available antibodies, and (iii) examination of the antifungal activity of protein extracts from germinating kernels. A preliminary report has been published (9). 


\section{MATERIALS AND METHODS}

Materials. Kernels of resistant corn genotypes GT-MAS:gk (23) and Mp420 (27) were obtained from the USDA/ARS, Insect Biology and Population Management Research Laboratory, Tifton, GA, and W. P. Williams (USDA/ARS, Mississippi State), respectively. Kernels of susceptible corn genotypes Pioneer 3154 and Deltapine G-4666 were obtained from Pioneer Hi-Bred International Inc., Johnston, IA, and Delta and Pine Land Company, Scott, MS, respectively. All kernels tested were free of fungicides, insecticides, and dyes normally used to treat seed prior to sale. Fungi used in bioassays were A. flavus strain AF13 (USDA/ARS/SRRC, New Orleans) and Fusarium moniliforme J. Sheld. isolate 40 (L. L. Black, Department of Plant Pathology and Crop Physiology, Louisiana State University, Baton Rouge), a kernel-rot pathogen that is a sensitive target of antifungal compounds (10).

Antibodies against two known antifungal proteins were used. Rabbit polyclonal antisera to corn zeamatin was prepared in C. P. Selitrennikoff's laboratory at the University of Colorado Health Sciences Center, Denver, and antibody to corn RIP was supplied by R. S. Boston (North Carolina State University, Raleigh). Reagents for polyacrylamide gel electrophoresis (PAGE) were purchased from Bio-Rad, Hercules, CA, and other chemicals were purchased from Sigma Chemical Co., St. Louis, unless otherwise stated in text.

Protein extraction. Kernels (20 g) of each genotype were surface-sterilized by immersion in $0.75 \% \mathrm{NaOCl}$ for $5 \mathrm{~min}$ and rinsed in three changes of sterile deionized water. These kernels were germinated by incubation at $25^{\circ} \mathrm{C}$ under $100 \%$ RH for 5 days (11). Kernels did not contact free water. Nongerminated kernels ( $20 \mathrm{~g})$ without these treatments served as a control. Kernels with visible radicles were considered germinated.

Protein extraction was carried out, using a procedure based on Cordero et al. (4) with modifications (10). Germinated and nongerminated kernels from each genotype were frozen in liquid nitrogen and ground to powder in an analytical mill (Tekmar A-10; Janke and Kunkel GmbH \& Co., Staufen, Germany). The extraction buffer was phosphate-citrate buffer $(84 \mathrm{mM}$ citric acid, $30 \mathrm{mM} \mathrm{Na} \mathrm{HPO}_{4}$ ), pH 2.8 (10), containing $14 \mathrm{mM}$ 2-mercaptoethanol and $6 \mathrm{mM}$ ascorbic acid. Chilled buffer $\left(4^{\circ} \mathrm{C}\right)$ was added to the kernel powder $(2 \mathrm{ml} / \mathrm{g}$ of dry kernel). Extraction was carried out at $4^{\circ} \mathrm{C}$ for $60 \mathrm{~min}$ with slow shaking $(60 \mathrm{rpm})$. The buffer extracts were centrifuged at $12,000 \times g$ at $4^{\circ} \mathrm{C}$ for $20 \mathrm{~min}$, and the supernatants were saved as crude extracts. The crude extract proteins were subjected to ultrafiltration with a Centriprep-10 with a 10-kDa cut-off membrane (Centriprep concentrator; Amicon Inc., Beverly, MA), and the $\mathrm{pH}$ was adjusted by exchanging phosphate buffer (10 mM phosphate, $\mathrm{pH} 7.0)$ during ultrafiltration. Each sample was concentrated eightfold, and the protein extracts were stored at $-80^{\circ} \mathrm{C}$.

PAGE. Increases in proteins during kernel imbibition and germination were examined for three of the four corn genotypes by sodium dodecyl sulfate-PAGE (SDS-PAGE) done according to Laemmli (18). SDS-PAGE was performed with $15 \%$ polyacrylamide resolving gels with $4 \%$ stacking gels. Electrophoresis was carried out in a Bio-Rad Mini-Protean II 2-D cell. Sigma low-range molecular-weight marker standards were used. After electrophoresis, proteins were stained with Coomassie brilliant blue R250.

Immunodetection of protein. Two SDS-PAGE methods were used: the first was the regular Laemmli (18) system of $15 \%$ resolving gels with $4 \%$ stacking gels and Tris-glycine buffer, and the second was 10 to $20 \%$ linear gradient gels with $4 \%$ stacking gels, in which tricine was substituted for glycine in the gel buffer for better separation of small proteins (26). Bio-Rad prestained SDS-PAGE and Kaleidoscope polypeptide standards were used. Proteins were transferred to polyvinylidene difluoride membranes (Immobilon P; Millipore, Bedford, MA) with a semidry transfer unit (Hoefer Scientific Instruments, San Francisco) with transfer buffer (48 mM Tris, $\mathrm{pH} 8.5,39 \mathrm{mM}$ glycine, $0.037 \%$ SDS [wt/vol], $20 \%$ methanol [vol/vol]) (17) at $100 \mathrm{~mA}$ for $1 \mathrm{~h}$. Blots were blocked for $1 \mathrm{~h}$ at room temperature in TBST buffer $(20 \mathrm{mM}$ Tris, $\mathrm{pH} 7.5,150 \mathrm{mM} \mathrm{NaCl}, 0.05 \%$ Tween 20 [vol/vol]) containing 5\% (wt/vol) nonfat milk powder. All antibody reactions were carried out in TBS (no Tween 20)-milk buffer. The blots were incubated with primary antiserum diluted $(1: 5,000)$ in TBSmilk buffer for at least $1 \mathrm{~h}$ at room temperature and washed twice (15 min each) with TBST (no milk). The blots were incubated with alkaline phosphatase-conjugated goat anti-rabbit immunoglobulin G secondary antibody (Bio-Rad) $(1: 3,000)$ in TBS-milk buffer for $1 \mathrm{~h}$ and were washed 3 times (5 min each) with TBST. Color development was performed with a Bio-Rad alkaline phosphatase kit according to the manufacturer's directions, using nitroblue tetrazolium chloride and 5-bromo-4-chloro-3-indoxylphosphate as substrates.

Antifungal activity assay. Purified RIP and zeamatin proteins from corn were tested for growth inhibition against A. flavus in microtiter plate assay. Each well contained purified protein of RIP at $0,75,150$, and $300 \mu \mathrm{g} / \mathrm{ml}$ or zeamatin at $0,12.5,25$, and $50 \mu \mathrm{g} / \mathrm{ml}$ at a final volume of $40 \mu \mathrm{l}$ with $4 \mu \mathrm{l}$ of potato dextrose broth (12 g/liter) and $6 \mu \mathrm{l}$ of $A$. flavus conidia $\left(10^{6} / \mathrm{ml}\right)$. All assays were conducted twice, and each had two replication wells. Sterilized Milli Q (Millipore) water was used as a control. The plates were incubated at $31^{\circ} \mathrm{C}$ for $12 \mathrm{~h}$. Hyphal development was examined by light microscopy.

Concentrated protein extracts of all four genotypes were tested in vitro for fungal growth inhibition. Nutrient medium (5\% V8 juice [vol/vol], $2 \%$ agar [wt/vol]) was autoclaved, cooled to $45^{\circ} \mathrm{C}$, and inoculated with conidia of A. flavus or F. moniliforme to achieve a final concentration of $104 / \mathrm{ml}$. Aliquots $(20 \mathrm{ml})$ of the warm inoculated medium were added quickly to 90 -mm-diameter petri plates and allowed to solidify. The inoculated plates were incubated at $25^{\circ} \mathrm{C}$ overnight before placing 7-mm-diameter sterile paper disks on the medium surface. Concentrated protein extracts $(20 \mu \mathrm{l})$ from each genotype were added to paper disks. Phosphate buffer $(20 \mu \mathrm{l}$, $\mathrm{pH}$ 7) added to disks served as a control. Petri plates were incubated at $25^{\circ} \mathrm{C}$ for 2 to 3 days and examined for inhibition of fungus growth, as indicated by clear zones around the paper disks.

\section{RESULTS}

SDS-PAGE revealed five protein bands that were present in higher concentrations in germinating than in nongerminating kernels of corn genotypes GT-MAS:gk, Pioneer 3154, and Deltapine G-4666 (Fig. 1). Of the five proteins, some were absent in nongerminated kernels but present in germinated kernels, and some were present in low concentrations in nongerminated kernels but increased to high concentrations in germinated kernels (Fig. 1, indicated by arrows). In the $22-\mathrm{kDa}$ region, a doublet was observed (Fig. 1) in which both components were increased in germinated kernels. There were no obvious differences between germinated kernels of resistant and susceptible genotypes.

Western blot analysis of the concentrated protein extracts from germinated and nongerminated kernels of all four genotypes was performed with antizeamatin and anti-RIP antibodies to determine whether proteins induced by germination were the known antifungal proteins. Results indicated that a single band reacted with antisera of 22-kDa zeamatin (Fig. 2). This protein was present at a high concentration in germinated kernels of all four genotypes, but its concentration was much lower in nongerminated kernels.

In western blot analysis with RIP antibody of nongerminated kernels (Fig. 3, lanes 1 through 4), two protein bands reacted with RIP antibody in all four genotypes, of which the $32-\mathrm{kDa}$ band probably was the proRIP form (inactive form) $(1,30)$ and the $18-\mathrm{kDa}$ peptide probably was one of the two peptides reported to form the active RIP, which was faint in GT-MAS:gk (Fig. 3, lane 1). However, germinated kernels of all four genotypes showed two 
protein bands (18 and $9 \mathrm{kDa}$ ) that reacted with RIP antisera (Fig. 3, lanes 5 through 8$)$. The larger protein band $(32 \mathrm{kDa})$ present in nongerminated kernels was absent and the smaller 18-kDa protein band was more intense in germinated kernels (Fig. 3, lanes 5 through 8).

Purified RIP and zeamatin proteins showed inhibitory activity against A. flavus growth at 75 and $50 \mu \mathrm{g} / \mathrm{ml}$, respectively (Fig. 4). The hyphae in treatments with purified antifungal protein were generally shorter than in the control. Antifungal activity assays showed that protein extracts from germinated kernels of all four genotypes inhibited A. flavus (Fig. 4A) and F. moniliforme (Fig. 4B) growth in vitro, as indicated by clear zones surrounding treated disks (Fig. 5). Larger inhibition zones were observed with

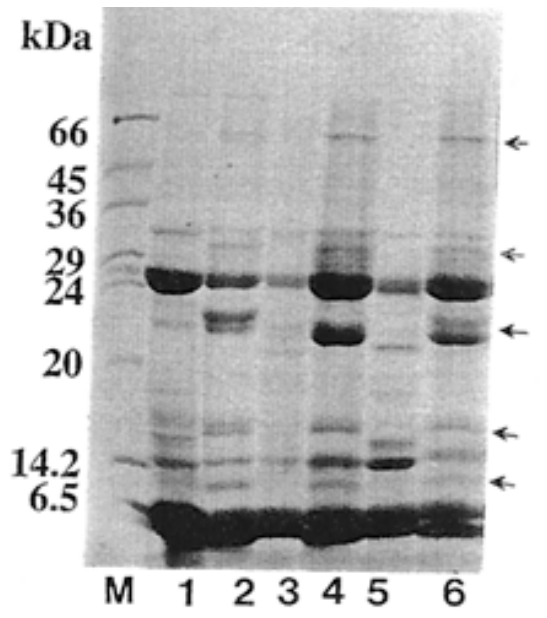

Fig. 1. Sodium dodecyl sulfate-polyacrylamide gel electrophoresis analysis of proteins from extracts of germinated corn kernels (lanes 2, 4, and 6) and nongerminated kernels (lanes 1, 3, and 5). Proteins were stained with Coomassie blue R-250. Molecular masses are indicated to the left, corresponding with the bands in lane M. Lanes 1 and 2, resistant genotype GT-MAS:gk; lanes 3 and 4, susceptible genotype Pioneer 3154; and lanes 5 and 6, susceptible genotype Deltapine G-4666. Arrows indicate the proteins that increased during germination.

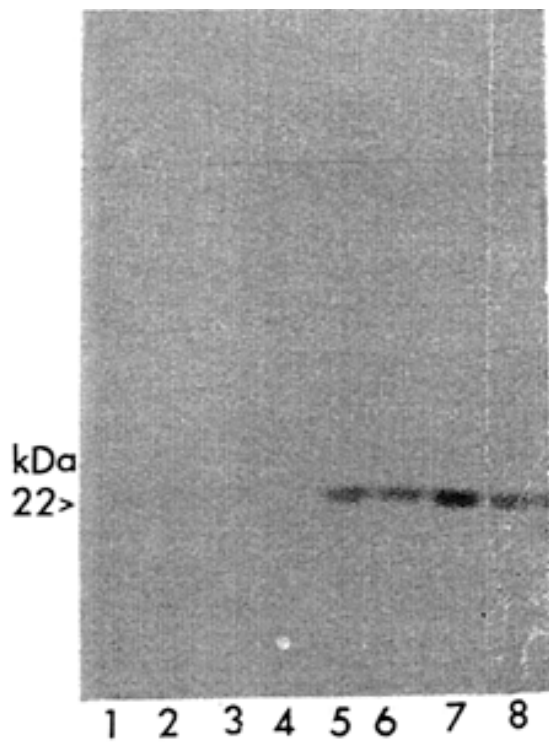

Fig. 2. Western blot analysis of corn kernel extracts from nongerminated (lanes 1 through 4) and germinated (lanes 5 through 8) kernels. Proteins were separated by sodium dodecyl sulfate-polyacrylamide gel electrophoresis according to Laemmli (18) with Tris-glycine buffer and detected with antiserum against 22-kDa corn zeamatin. Lanes 1 and 5, resistant genotype GT-MAS:gk; lanes 2 and 6, susceptible genotype Pioneer 3154; lanes 3 and 7, resistant genotype MP420; and lanes 4 and 8, susceptible genotype Deltapine G-4666. All genotypes show induction and accumulation of a $22-\mathrm{kDa}$ protein during germination. the extracts from germinated kernels of susceptible genotypes Pioneer 3154 and Deltapine G-4666 (Fig. 5, p and d) than were observed with resistant genotypes GT-MAS:gk and MP420 (Fig. 5, $\mathrm{m}$ and $\mathrm{t}$ ). In contrast, the extracts from nongerminated kernels of
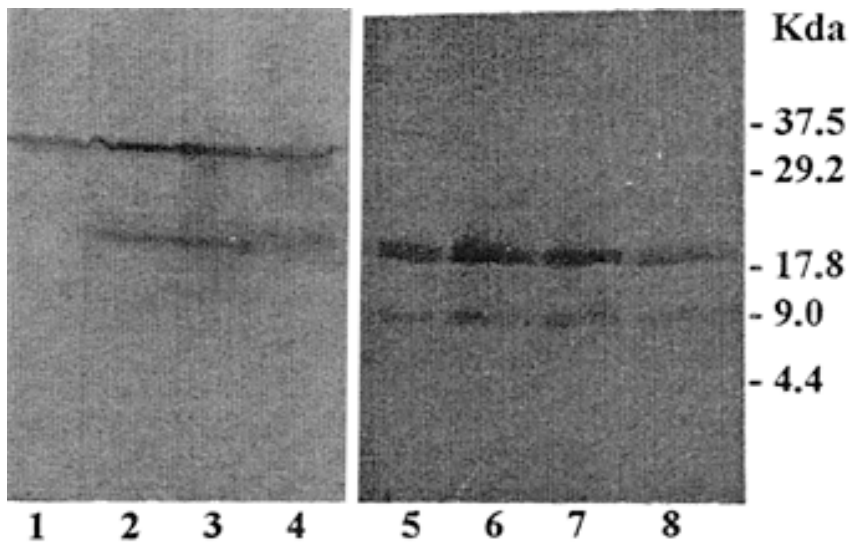

Fig. 3. Western blot analysis of corn extracts from nongerminated (lanes 1 through 4) and germinated (lanes 5 through 8) kernels. Proteins were separated by sodium dodecyl sulfate-polyacrylamide gel electrophoresis according to Schägger and von Jagow (26) with Tris-tricine buffer and detected with antiserum against corn ribosome-inactivating protein. Lanes 1 and 5, resistant genotype GT-MAS:gk; lanes 2 and 6, susceptible genotype Pioneer 3154; lanes 3 and 7, resistant genotype MP420; and lanes 4 and 8, susceptible genotype Deltapine G-4666.

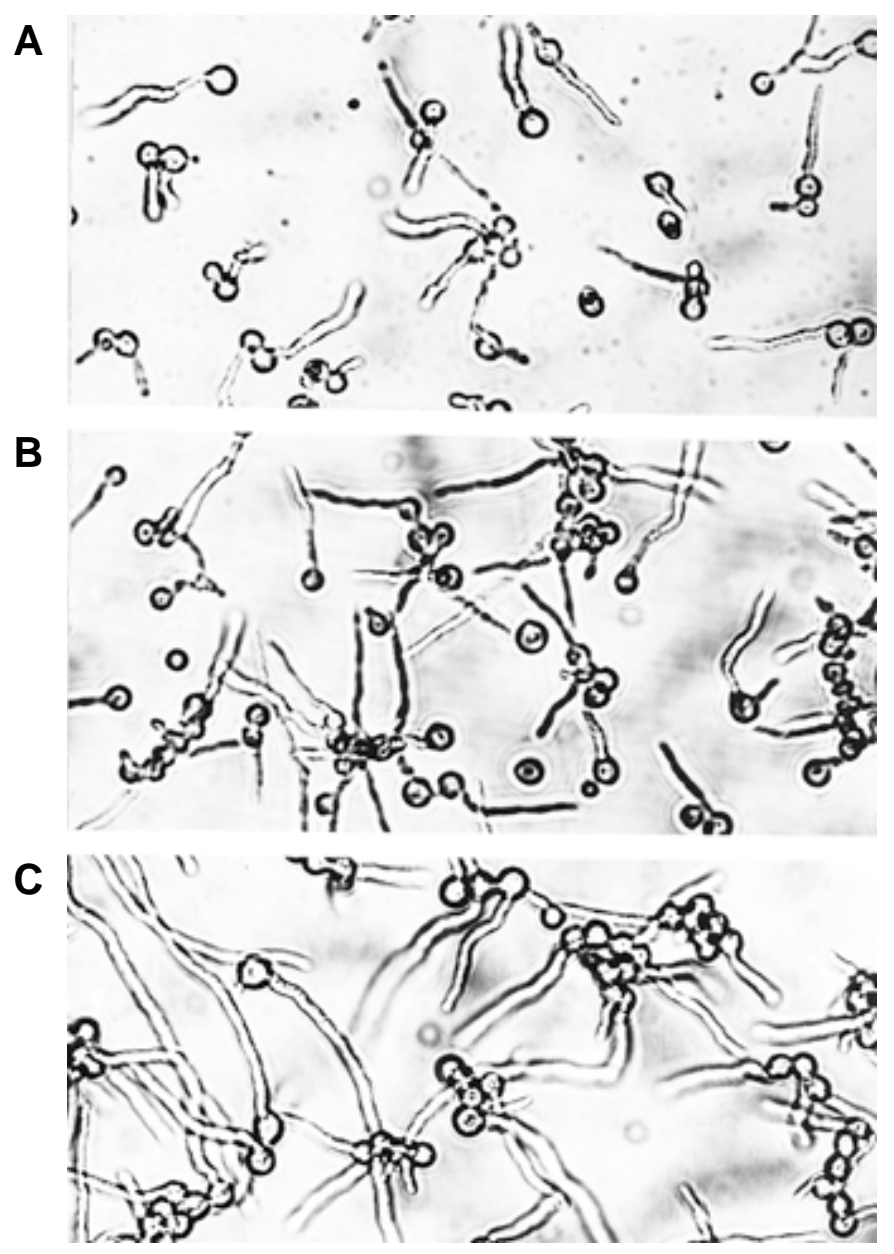

Fig. 4. Bioassays of purified ribosome-inactivating protein (RIP) and zeamatin from corn that inhibit Aspergillus flavus. The concentration of RIP was $0,75,150$, and $300 \mu \mathrm{g} / \mathrm{ml}$, and the concentration of zeamatin was $0,12.5,25$, and $50 \mu \mathrm{g} / \mathrm{ml}$. RIP and zeamatin strongly inhibited fungal growth at $\mathbf{A}, 75 \mu \mathrm{g} / \mathrm{ml}$ and $\mathbf{B}, 50 \mu \mathrm{g} / \mathrm{ml}$, respectively, compared to $\mathbf{C}$, the control. 
the resistant genotypes (GT-MAS:gk and Mp420) caused larger inhibition zones than did the extracts from the susceptible genotypes (Pioneer 3154 and Deltapine G-4666) (Fig. 6) (10).

\section{DISCUSSION}

In an earlier report (11), we showed that germinating corn kernels accumulated markedly less aflatoxin than did nongerminated kernels of the same genotypes. The current results demonstrate that germinating kernels contained at least five proteins that were induced or present at higher levels than in nongerminating kernels. Immunological analysis revealed that three of these proteins were zeamatin- and RIP-like. Antifungal bioassays showed that the purified RIP and zeamatin inhibited A. flavus hyphal growth. Furthermore, protein extracts of germinated kernels from all four tested corn genotypes had stronger antifungal activities against $A$. flavus and $F$. moniliforme than did extracts of nongerminated kernels. These results suggest that germination, which resulted in increased resistance to aflatoxin production (11), may be related to the induction of antifungal proteins. The phenomenon of germinationbased resistance in corn kernels has been reported elsewhere (16). Keller et al. (16) found that A. flavus, A. nidulans, and A. parasiticus grew poorly on embryo tissues from germinating corn kernels. The resistance to Aspergillus infection and concomitant toxin production of germinating corn embryos suggested the generation of antifungal compound(s) in germinating corn (16).

The biochemical basis of germination-associated resistance $(2$, $11,16,20)$ is largely unknown. Our results yielded some insight into germination-associated resistance, namely that it may be due to the induction of antifungal proteins and, perhaps, other proteins. These proteins may act synergistically to provide greater protection from pathogens than any one could provide by itself (5). RIPand zeamatin-like protein induction, in this study, increased to a high concentration during germination of kernels. ProRIP-like protein was the primary form in dry kernels, and the proRIP-like protein converted into the likely active forms with smaller molecular weights, as reported $(1,30)$ in both resistant and susceptible genotypes. Roberts and Selitrennikoff (24) reported that zeamatin may exert its antifungal activity by a membrane permeabilization mechanism. High zeamatin concentrations permeabilize fungal membranes, causing cell death, whereas lower concentrations do not cause death directly but may interact with the membrane to facilitate penetration of other compounds (29), resulting in synergistic killing. If this model is correct, then the increased levels of active forms of both RIP and zeamatin in germinating kernel ex- tracts from all four genotypes would be expected to support the increased antifungal activities noted in this study and the increased resistance of germinating kernels in an earlier report (11).

It has been reported that in corn a RIP is synthesized specifically in kernels as an inactive 32-kDa zymogen (proRIP), which is activated by proteolysis during germination, resulting in two active forms of RIP of 16.5 and $8.5 \mathrm{kDa}(1,30)$. However, SDSPAGE and Western blot analyses in our studies resolved the protein into two polypeptides with molecular masses of $\approx 18$ and $9 \mathrm{kDa}$. The disparity in reported molecular masses is probably not significant and may result in inconsistent results due to use of different SDS-PAGE gels (glycine or tricine).

Because we found nearly an equal quantity of RIP in both resistant and susceptible genotypes, this protein by itself may not explain field resistance to A. flavus. Other proteins may act synergistically with RIP, which may explain observed differences. Alternatively, the cellular distribution of RIP may be greater in specific tissues in resistant kernels, whereas the concentrations in whole kernels may be not different in the two genotypes. In vivo, RIP may be produced or compartmentalized with other antifungal proteins, such as chitinase, glucanase, and zeamatin $(5,14,24)$, to facilitate defense. Barley RIP confers protection of transgenic tobacco

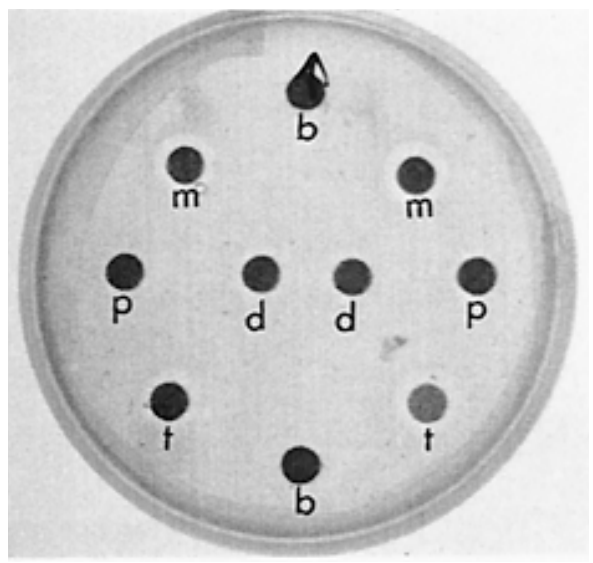

Fig. 6. Bioassays of concentrated protein extracts of dry nongerminated corn kernels that inhibit Aspergillus flavus. Extract was from resistant genotype GT-MAS:gk (m), susceptible genotype Pioneer 3154 (p), resistant genotype Mp420 (t), and susceptible genotype Deltapine G-4666 (d). Phosphate buffer (b), $\mathrm{pH} 7$, was a control. The clear zone around the paper disks indicates inhibition of fungal growth. The photograph was taken from the underside of the petri dish.
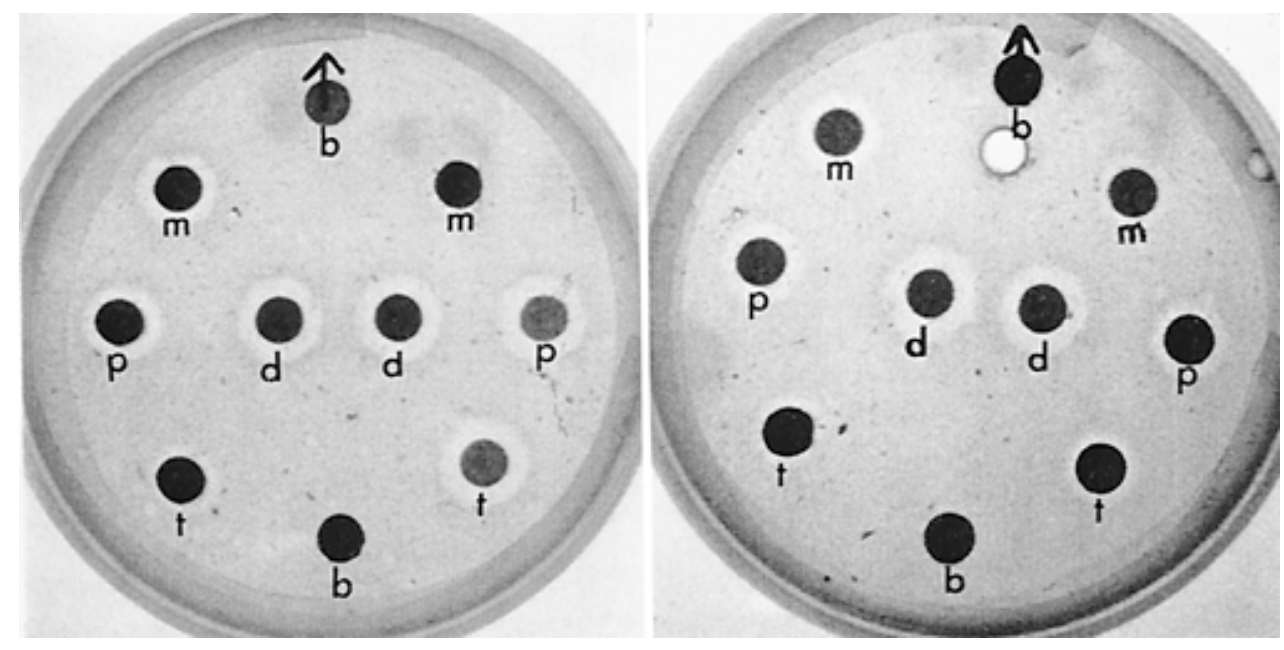

Fig. 5. Bioassays of concentrated protein extracts of germinated corn kernels that inhibit Aspergillus flavus (left panel) and Fusarium moniliforme (right panel). Extract was from resistant genotype GT-MAS:gk (m), susceptible genotype Pioneer 3154 (p), resistant genotype Mp420 (t), and susceptible genotype Deltapine G-4666 (d). Phosphate buffer (b), pH 7, was a control. The clear zone around the paper disks indicates inhibition of fungal growth. The photograph was taken from the underside of the petri dish. 
plants against Rhizoctonia solani $(15,22)$, and tobacco lines that coexpress barley chitinase and RIP show enhanced protection (15).

Our aims are to understand the biochemical mechanisms and molecular basis that regulate induced resistance in corn to facilitate the development of host resistance to aflatoxin contamination. The results reported here indicate that other antifungal proteins may exist that may afford corn resistance to mycotoxin production through modification of corn genotypes supporting lower toxin production. The specific function or role of each protein induced or preformed in corn kernels remains to be determined. One approach, using biotechnology to gain more insight into the molecular characterization and regulation of expression of these proteins, is to study the phenotypic changes in transgenic plants that overexpress the proteins. To this end, expression vectors could be constructed to express these proteins singly or in different combinations under the control of selected plant promoters. Experiments with developed transgenic plants should increase our understanding of the function of these proteins in corn kernels when evaluating for desired resistance to infection by Aspergillus or Fusarium and mycotoxin accumulation.

\section{ACKNOWLEDGMENTS}

This project was supported by USDA Cooperative Agreement 586435-2-130. A. D. Mehta was supproted by USDA National Research Initiative (95-37304-2250). We thank H. Holen, P. Harris, and A. Guitroz, SRRC, USDA-ARS, for technical assistance; J. W. Cary, SRRC, USDA-ARS, and P. Ozias-Akins, University of Georgia, Tifton, for reviewing the manuscript.

\section{LITERATURE CITED}

1. Bass, H. W., Webster, C., O'Brian, G. R., Roberts, K. M., and Boston, R. S. 1992. A maize ribosome-inactivating protein is controlled by the transcriptional activator Opaque-2. Plant Cell 4:225-234.

2. Brown, R. L., Cotty, P. J., Cleveland, T. E., and Widstrom, N. W. 1993. Living maize embryo influences accumulation of aflatoxin in maize kernels. J. Food Prot. 56:967-971.

3. Cleveland, T. E., and Bhatnagar, D. 1992. Molecular strategies for reducing aflatoxin levels in crops before harvest. Pages 205-228 in: Molecular Approaches to Improving Food Quality and Safety. D. Bhatnagar and T. E. Cleveland, eds. Van Nostrand Reinhold, New York.

4. Cordero, M. J., Raventós, D., and Segundo, B. S. 1992. Induction of PR protein in germinating maize seeds infected with the fungus Fusarium moniliforme. Physiol. Mol. Plant Pathol. 41:189-200.

5. Darnetty, Leslie, J. F., Muthukrishnan, S., Swegle, M., Vigers, A. J., and Selitrennikoff, C. P. 1993. Variability in antifungal proteins in the grains of maize, sorghum and wheat. Physiol. Plant. 88:339-349.

6. Dixon, R. A., and Harrison, M. 1990. Activation, structure and organization of genes involved in microbial defense in plants. Adv. Genet. 28: 165-234.

7. Gasser, C., and Fraley, R. T. 1989. Genetically engineering plants for crop improvement. Science 244:1293-1299.

8. Guo, B. Z. 1995. Mechanisms of resistance to aflatoxin accumulation by Aspergillus flavus in maize genotype GT-MAS:gk. Ph.D. dissertation. Louisiana State University, Baton Rouge.

9. Guo, B. Z., Brown, R. L., Cleveland, T. E., Lax, A. R., and Russin, J. S. 1996. Induction of proteins and resistance to Aspergillus flavus during corn kernel germination. Page 22 in: Proc. Aflatoxin Elimination Workshop. J. Robens and T. E. Cleveland, eds. U.S. Department of Agriculture,
Agricultural Research Service, Washington, D.C.

10. Guo, B. Z., Brown, R. L., Lax, A. R., Cleveland, T. E., Russin, J. S., and Widstrom, N. W. Protein profiles and antifungal activities of kernel extracts from corn genotypes resistant and susceptible to Aspergillus flav$u s$. J. Food Prot. In press.

11. Guo, B. Z., Russin, J. S., Brown, R. L., Cleveland, T. E., and Widstrom, N. W. 1996. Resistance to aflatoxin contamination in corn as influenced by relative humidity and kernel germination. J. Food Prot. 59:276-281.

12. Guo, B. Z., Russin, J. S., Cleveland, T. E., Brown, R. L., and Damann, K. E. 1996. Evidence for cutinase production by Aspergillus flavus and its possible role in infection of corn kernels. Phytopathology 86:824-829.

13. Guo, B. Z., Russin, J. S., Cleveland, T. E., Brown, R. L., and Widstrom, N. W. 1995. Wax and cutin layers in maize kernels associated with resistance to aflatoxin production by Aspergillus flavus. J. Food Prot. 58: 296-300.

14. Huynh, Q. K., Hironaka, C. M., Levine, E. B., Smith, C. E., Borgmeyer, J. R., and Shah, D. M. 1992. Antifungal proteins from plants: Purification, molecular cloning, and antifungal properties of chitinases from maize seed. J. Biol. Chem. 267:6635-6640.

15. Jach, G., Görnhardt, B., Mundy, J., Logemann, J., Pinsdorf, E., Leah, R., Schell, J., and Maas, C. 1995. Enhanced quantitative resistance against fungal disease by combinatorial expression of different barley antifungal proteins in transgenic tobacco. Plant J. 8:97-109.

16. Keller, N. P., Butchko, R. A. E., Sarr, B., and Phillips, T. D. 1994. A visual pattern of mycotoxin production in maize kernels by Aspergillus spp. Phytopathology 84:483-488.

17. Kyhse-Andersen, J. 1984. Electroblotting of multiple gels: A simple apparatus without buffer tank for rapid transfer of proteins from polyacrylamide to nitrocellulose. J. Biochem. Biophys. Methods 10:203-209.

18. Laemmli, U. K. 1970. Cleavage of structural proteins during the assembly of the head of the bacteriophage T4. Nature (Lond.) 277:680-685.

19. Lamb, C. J., Lawton, M. A., Dron, M., and Dixon, R. A. 1989. Signals and transduction mechanism for activation of plant defenses against microbial attack. Cell 56:215-224.

20. Lindsey, D. L., and Turner, R. B. 1975. Inhibition of growth of Aspergillus flavus and Trichoderma verde by peanut embryos. Mycopathologia 55:149-152.

21. Linthorst, H. J. M. 1991. Pathogenesis-related proteins of plants. Crit. Rev. Plant Sci. 10:123-150.

22. Logemann, J., Jach, G., Tommerup, H., Mundy, J., and Schell, J. 1992. Expression of a barley ribosome-inactivating protein leads to increased fungal protection in transgenic tobacco plants. Bio/Technology 10:305308.

23. McMillian, W. W., Widstrom, N. W., and Wilson, D. M. 1993. Registration of GT-MAS:gk maize germplasm. Crop Sci. 33:882.

24. Roberts, W. K., and Selitrennikoff, C. P. 1990. Zeamatin, an antifungal protein from maize with membrane-permeabilizing activity. J. Gen. Microbiol. 136:1771-1778.

25. Russin, J. S., Guo, B. Z., Tubujika, K. M., Brown, R. L., Cleveland, T. E., and Widstrom, N. W. 1997. Comparison of kernel wax from corn genotypes resistant or susceptible to Aspergillus flavus. Phytopathology 87: 529-533.

26. Schägger, H., and von Jagow, G. 1987. Tricine-sodium dodecyl sulfatepolyacrylamide gel electrophoresis for the separation of proteins in the range from 1 to $100 \mathrm{kDa}$. Anal. Biochem. 166:368-379.

27. Scott, G. E., and Zummo, N. 1992. Registration of Mp420 germplasm line of maize. Crop Sci. 32:1296.

28. Staskawicz, B. J., Ausubei, F. M., Baker, B., Ellis, J. G., and Jones, J. D. G. 1995. Molecular genetics of plant disease resistance. Science 268:661667.

29. Vigers, A. J., Roberts, W. K., and Selitrennikoff, C. P. 1991. A new family of plant antifungal proteins. Mol. Plant-Microbe Interact. 4:315-323.

30. Walsh, T. A., Morgan, A. E., and Hey, T. D. 1991. Characterization and molecular cloning of a proenzyme form of a ribosome-inactivating protein from maize. J. Biol. Chem. 266:23422-23427. 